\title{
Laparoscopic vs. Open Surgery for Stage II/III Colon Cancer Patients With Body Mass Index $>25 \mathrm{~kg} / \mathrm{m}^{2}$
}

\author{
KEISUKE KAZAMA ${ }^{1}$, MASAKATSU NUMATA ${ }^{1}$, TORU AOYAMA ${ }^{1}$, ATSUSHI ONODEARA ${ }^{1}$, \\ KENTARO HARA $^{1}$, YOSUKE ATSUMI ${ }^{1}$, HIROSHI TAMAGAWA ${ }^{1}$, TENI GODAI ${ }^{2}$, \\ HIROYUKI SAEKI ${ }^{3}$, YUSUKE SAIGUSA ${ }^{4}$, HIRONAO OKAMOTO ${ }^{5}$, MANABU SHIOZAWA $^{5}$, \\ TAKASHI OSHIMA $^{5}$, NORIO YUKAWA ${ }^{1}$, MUNETAKA MASUDA $^{1}$ and YASUSHI RINO ${ }^{1}$ \\ ${ }^{1}$ Department of Surgery, Yokohama City University, Yokohama, Japan; \\ ${ }^{2}$ Department of Surgery, Fujisawa Shounandai Hospital, Fujisawa, Japan; \\ ${ }^{3}$ Department of Surgery, Yokohama Minami Kyosai Hospital, Yokohama, Japan; \\ ${ }^{4}$ Department of Biostatistics, Yokohama City University, Yokohama, Japan; \\ ${ }^{5}$ Department of Gastrointestinal Surgery, Kanagawa Cancer Center, Yokohama, Japan
}

\begin{abstract}
Aim: To compare long- and short-term outcomes of laparoscopic surgery with those of open surgery for patients with colorectal cancer and body mass index over $25 \mathrm{~kg} / \mathrm{m}^{2}$. Patients and Methods: This multicentre, retrospective study analysed clinical records and identified 178 patients with body mass index over $25 \mathrm{~kg} / \mathrm{m}^{2}$ who underwent surgery for colon and rectosigmoid cancer between 2000 and 2016. After applying propensity score matching, 96 patients were finally included. The primary outcome was the 3-year recurrence-free survival rate, and the secondary outcomes were short-term results during and after surgery. Results: The 3-year recurrence-free survival rates were similar for the laparoscopic and open surgery groups. The laparoscopic surgery group had longer operative times but less blood loss and shorter periods of hospital stay. There were no differences in incidence of postoperative complications. Conclusion: Laparoscopic and open surgeries had similar longterm outcomes for obese patients. Laparoscopic surgery is an effective option for this population.
\end{abstract}

In recent years, laparoscopic surgery for colon cancer (LAC) has become widespread worldwide (1-4). There has been a growing prevalence of obesity, 640 million in 2014 according to Imperial College London and the World Health Organization (5). In Japan, $31.3 \%$ of males and $20.6 \%$ of

This article is freely accessible online.

Correspondence to: Keisuke Kazama, Department of Surgery, Yokohama City University, Address: 3-9 Fukuura, Kanazawa-ku, Yokohama 236-0004, Japan. Tel: +81 457872800, e-mail: c_falcon_kk@yahoo.co.jp

Key Words: Body mass index, colonic neoplasms, colorectal neoplasms, laparoscopy, obesity. females have a body mass index (BMI) over $25 \mathrm{~kg} / \mathrm{m}^{2}$. This health issue will lead to increased laparoscopic surgeries for the obese patients worldwide.

There are conflicting opinions about the use of LAC in obese patients. In terms of short-term outcomes, randomized controlled trials have generally shown advantages of the minimal invasiveness of LAC in terms of reduced blood loss, earlier recovery, and lower complication rates compared with those of open colectomy (OC). When the focus is obese patients, however, increased postoperative complications (6), reoperation rates (7) and conversion rates (8-11) have been reported for LAC. A possible explanation for this inverse effect may be the technical difficulty in maintaining adequate surgical views in the presence of bulky visceral fat.

With respect to long-term outcomes, only one report has retrospectively demonstrated the equivalence of LAC to OC for obese patients (12). By contrast, subgroup analysis of a randomized-controlled trial aiming to show the noninferiority outcomes of LAC to OC in Japan showed poorer overall survival (OS) for those treated with LAC than for those who underwent OC (13), likely due to the difficulties in performing qualified complete mesenteric excision (CME) with central vascular ligation (CVL) for obese patients.

Currently, there are conflicting opinions regarding whether LAC or OC is more suitable for obese patients. We performed this study to compare short- and long-term outcomes of LAC versus $\mathrm{OC}$ for obese patients so as to begin to help resolve this controversy.

\section{Patients and Methods}

Study design. The medical records of Yokohama City University and two affiliated hospitals were retrospectively reviewed. Between April 2000 and March 2016, a total of 961 patients with stage II/III colon and rectosigmoid cancer underwent resection of the primary site at 


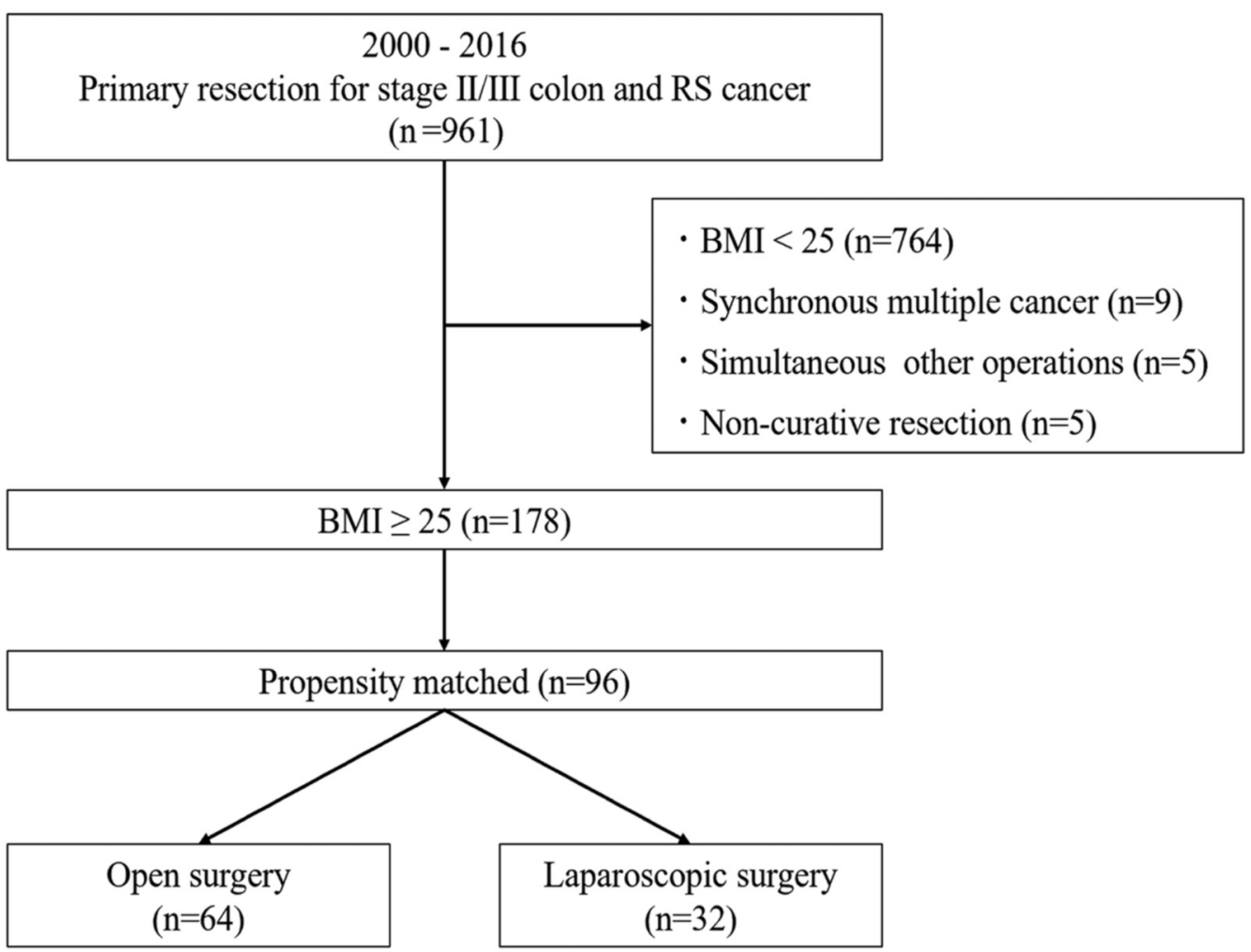

Figure 1. Study design. BMI: Body mass index; RS: rectosigmoid.

these facilities. Of these, we excluded 764 patients with BMI $<25$ $\mathrm{kg} / \mathrm{m}^{2}$, nine with synchronous multiple cancer, five with simultaneous surgery for other organs, and five with non-curative resection. Finally, a total of 178 patients were enrolled. Using propensity score matching, 96 matched patients were divided into two groups: the OC group $(n=64)$ and the LAC surgery group $(n=32)$ (Figure 1).

Outcomes. The primary outcome was the 3 -year relapse-free survival (RFS) rate; secondary (short-term) outcomes were operative time, blood loss, length of postoperative hospital stay and incidence of postoperative complications.

Operative procedure. The choice of laparoscopic or open surgery was entrusted to each surgical team. For open surgery, a midline laparotomy with appropriate length of incision was performed. Mobilization of the colon and rectum from the lateral side was followed by vessel and bowel ligation and anastomosis. In laparoscopic surgery, a 5-port method was used. Initial laparoscopic access into the abdomen was achieved via the umbilical port. Once pneumoperitoneum was established, four additional ports were added. Mobilization of the mesocolon with the medial approach was performed first, followed by the lateral approach and lymph node dissection. In both procedures, the appropriate extent of lymph node dissection with CVL was performed along with CME, according to Japanese Society for Cancer of the Colon and Rectum (JSCCR) guidelines (14). Reconstruction of the colon was performed using functional-end-to-end-anastomosis; reconstruction of the rectum used the double-stapling technique.
Follow-up. Patients were followed up every 6 months for more than 3 years, including computed tomography and colonoscopy. RFS was defined as the period between surgery and the date of either death, tumour recurrence, or final follow-up.

Evaluations. Pathological factors recorded included tumour depth, nodal status and staging, according to the JSCCR guidelines (ninth). Postoperative surgical complications were defined as those with Clavien-Dindo classification grade 2 or more occurring within 30 days after the operation or during hospitalization (15).

Propensity-score matching. Two-to-one propensity score matching was performed according to patient characteristics: Pathological stage (II/III) tumour diameter $(<50 / \geq 50 \mathrm{~mm})$, tumour location (right-sided/left-sided), extent of lymph node dissection (D1,2/D3), and preoperative ileus (yes/no). These factors were selected according to the statistically significant differences between prematched groups and their clinical importance.

Statistical analysis. The chi-square test and Mann-Whitney $U$-test were performed to compare the two surgical groups. The KaplanMeier method was used to calculate the 3-year RFS rates, and the log-rank test was performed to compare the survival rates between the groups. Univariate and multivariate Cox proportional hazard models were applied to calculate hazard ratios (HRs) for the RFS. All statistical analyses were performed using EZR, a graphical user interface for R (The R Foundation for Statistical Computing, Vienna, Austria; version 2.13.0). Two-sided $p$-values were 
Table I. Patient background characteristics according to study group.

\begin{tabular}{|c|c|c|c|c|}
\hline Factor & & $\mathrm{OC}(\mathrm{N}=64)$ & LAC $(\mathrm{N}=32)$ & $p$-Value \\
\hline Age, years & Median (range) & $71(40-95)$ & $69(49-88)$ & 0.297 \\
\hline \multirow[t]{2}{*}{ Gender, n (\%) } & Male & $33(51.6 \%)$ & $21(65.6 \%)$ & 0.275 \\
\hline & Female & $31(48.4 \%)$ & $11(34.4 \%)$ & \\
\hline BMI, $\mathrm{kg} / \mathrm{m}^{2}$ & Median (range) & $26.9(25.0-34.2)$ & $27.8(25.0-35.6)$ & 0.261 \\
\hline \multirow[t]{2}{*}{ ASA-PS, n (\%) } & Class 1,2 & $42(65.6 \%)$ & $25(78.1 \%)$ & 0.245 \\
\hline & Class 3 & $22(34.4 \%)$ & $7(21.9 \%)$ & \\
\hline \multirow[t]{2}{*}{ Tumour location, n (\%) } & Right-sided & $21(32.8 \%)$ & $11(34.4 \%)$ & $>0.99$ \\
\hline & Left-sided & $43(67.2 \%)$ & $21(65.6 \%)$ & \\
\hline \multirow[t]{2}{*}{$\mathrm{LND}, \mathrm{n}(\%)$} & $\mathrm{D} 1,2$ & $25(39.1 \%)$ & $10(31.3 \%)$ & 0.506 \\
\hline & D3 & $39(60.9 \%)$ & $22(68.7 \%)$ & \\
\hline \multirow[t]{2}{*}{ Preoperative ileus, n (\%) } & Yes & $7(10.9 \%)$ & $3(9.4 \%)$ & $>0.99$ \\
\hline & No & $57(89.1 \%)$ & $29(90.6 \%)$ & \\
\hline \multirow[t]{2}{*}{ Stoma, n $(\%)$} & Yes & $60(93.7 \%)$ & $32(100 \%)$ & 0.298 \\
\hline & No & $4(6.3 \%)$ & 0 & \\
\hline \multirow[t]{2}{*}{ Adjuvant chemotherapy, n (\%) } & Yes & $42(65.6 \%)$ & $22(68.8 \%)$ & 0.821 \\
\hline & No & $22(34.4 \%)$ & $10(31.2 \%)$ & \\
\hline
\end{tabular}

BMI: Body mass index; ASA-PS: American Society of Anesthesiologists Physical Status; LND: lymph node dissection; OC: open surgery; LAC: laparoscopic surgery.

calculated, and differences were considered to be statistically significant at $p<0.05$.

Ethics. Study protocols were approved by the Institutional Review Board of Yokohama City University (approval no. 170,700,003). This study was performed in accordance with the ethical standards laid down in the 1964 Declaration of Helsinki and its later amendments. Instead of obtaining informed consent from each patient, the study protocols were provided to patients via a notice board in each hospital and on hospital websites.

\section{Results}

Characteristics of enrolled patients. Table I shows the clinical characteristics of the patients in the two surgical groups. There were no significant differences between the two groups with respect to age, sex, BMI, American Society of Anesthesiologist Physical Status classification, tumour location, stoma, or adjuvant chemotherapy. There were patients with stomas only in the OC group. The median follow-up period was 38.5 months for patients overall.

Pathological findings of the two groups are displayed in Table II. Both patients with pT4b tumours were operated on using open procedures; however, because of propensity score matching, there were no significant differences between the groups with respect to any parameter.

Short-term outcomes. Short-term outcomes are displayed in Table III. Compared to the OC group, the LAC group had longer operative times (163 $\mathrm{min} v s .196 \mathrm{~min}, p=0.004)$, less blood loss (157 vs. $10 \mathrm{ml}, p<0.001)$ and shorter postoperative hospitalization (12 vs. 10 days, $p=0.011)$. Only one patient
(3.1\%) in the LAC group was converted to open surgery. The incidence of postoperative complications (grade 2 or more) were similar for the two groups (25.0\% vs. $21.9 \%, p=0.803)$. In both groups, frequent complications were ileus, followed by anastomotic leakage and surgical site infection (SSI). There were no significant differences in complication rates between the two groups.

RFS and details ofsites of recurrence. The Kaplan-Meier curves for RFS are presented in Figure 2. The 3-year RFS after surgery was $82.2 \%$ (95\% confidence intervaI=68.2$90.4 \%$ ) in the OC group and $85.5 \%$ (95\% confidence intervaI $=60.0-95.3 \%$ ) in the LAC group (not significant: $p=0.581$ ). Recurrences were observed in $14.1 \%$ in the OC group and $9.4 \%$ in the LAC group, of which liver metastasis was observed most frequently (not significantly different; Table IV). Recurrence at local sites (3.1\%) and extraregional lymph nodes $(1.6 \%)$ were seen only in the OC group, whereas recurrence in the peritoneum was seen only in the LAC group (3.1\%).

\section{Discussion}

We found that LAC was equivalent to $\mathrm{OC}$ in terms of longterm outcome and was superior to $\mathrm{OC}$ in terms of many short-term outcomes for obese patients undergoing surgery for colorectal cancer. To the best of our knowledge, this is the first such retrospective study with propensity matching.

Several studies compared outcomes for LAC between obese patients and non-obese patients. Nevertheless, on the basis of these studies, it was difficult to determine whether or not LAC 
Table II. Pathological findings according to study group.

\begin{tabular}{|c|c|c|c|c|}
\hline Factor & & OC $(\mathrm{N}=64), \mathrm{n}(\%)$ & LAC (N=32), n (\%) & $p$-Value \\
\hline \multirow[t]{2}{*}{ Histology } & Well-/moderately differentiated & $59(92.2 \%)$ & $31(96.9 \%)$ & 0.660 \\
\hline & Other & $5(7.8 \%)$ & $1(3.1 \%)$ & \\
\hline \multirow[t]{2}{*}{ Tumour diameter } & $<50 \mathrm{~mm}$ & $39(60.9 \%)$ & $21(65.6 \%)$ & 0.823 \\
\hline & $\geq 50 \mathrm{~mm}$ & $25(39.1 \%)$ & $11(34.4 \%)$ & \\
\hline \multirow[t]{5}{*}{$\mathrm{pT}$} & $\mathrm{T} 1$ & $2(3.1 \%)$ & $2(6.3 \%)$ & 0.381 \\
\hline & $\mathrm{T} 2$ & $4(6.3 \%)$ & $5(15.6 \%)$ & \\
\hline & $\mathrm{T} 3$ & $40(62.5 \%)$ & $20(62.5 \%)$ & \\
\hline & T4a & $16(25.0 \%)$ & $5(15.6 \%)$ & \\
\hline & $\mathrm{T} 4 \mathrm{~b}$ & $2(3.1 \%)$ & 0 & \\
\hline \multirow[t]{3}{*}{$\mathrm{pN}$} & pNO & $38(59.4 \%)$ & $17(53.1 \%)$ & 0.637 \\
\hline & $\mathrm{pN} 1$ & $20(31.2 \%)$ & $10(31.3 \%)$ & \\
\hline & $\mathrm{pN} 2$ & $6(9.4 \%)$ & $5(15.6 \%)$ & \\
\hline \multirow[t]{2}{*}{ pStage } & II & $38(59.4 \%)$ & $17(53.1 \%)$ & 0.663 \\
\hline & III & $26(40.6 \%)$ & $15(46.9 \%)$ & \\
\hline \multirow[t]{2}{*}{ Vascular invasion } & Yes & $19(29.7 \%)$ & $14(43.8 \%)$ & 0.181 \\
\hline & No & $45(70.3 \%)$ & $18(56.2 \%)$ & \\
\hline \multirow[t]{2}{*}{ Lymphatic invasion } & Yes & $31(48.4 \%)$ & $20(62.5 \%)$ & 0.278 \\
\hline & No & $33(51.6 \%)$ & $12(37.5 \%)$ & \\
\hline
\end{tabular}

pT: Pathological T factor; pN: pathological N factor; pStage: pathological stage; OC: open surgery; LAC: laparoscopic surgery.

Table III. Short-term outcomes according to study group.

\begin{tabular}{|c|c|c|c|c|}
\hline Factor & & $\mathrm{OC}(\mathrm{N}=64)$ & LAC $(\mathrm{N}=32)$ & $p$-Value \\
\hline Operative time, $\min$ & Median (range) & $163(57-446)$ & $196(106-373)$ & 0.004 \\
\hline Blood loss, ml & Median (range) & $157(1-1160)$ & $10(1-500)$ & $<0.001$ \\
\hline Conversion to open surgery, $\mathrm{n}(\%)$ & Yes & & $1(3.1 \%)$ & \\
\hline \multirow[t]{13}{*}{ Complications, $\mathrm{n}(\%)^{*}$} & Total & $16(25.0 \%)$ & $7(21.9 \%)$ & 0.803 \\
\hline & Ileus & $8(12.5 \%)$ & $4(12.5 \%)$ & \\
\hline & Anastomotic leakage & $3(4.7 \%)$ & $2(6.3 \%)$ & \\
\hline & SSI & $2(3.1 \%)$ & $1(3.1 \%)$ & \\
\hline & Delirium & $1(1.6 \%)$ & $1(3.1 \%)$ & \\
\hline & Renal dysfunction & $2(3.1 \%)$ & 0 & \\
\hline & Liver dysfunction & 0 & $1(3.1 \%)$ & \\
\hline & Gastric ulcer & $1(1.6 \%)$ & 0 & \\
\hline & Pneumonia & $1(1.6 \%)$ & 0 & \\
\hline & Thrombosis & $1(1.6 \%)$ & 0 & \\
\hline & Heart failure & $1(1.6 \%)$ & 0 & \\
\hline & Diarrhoea & $1(1.6 \%)$ & 0 & \\
\hline & Mortality & 0 & 0 & \\
\hline Postoperative hospital stay, days & Median (range) & $12(7-76)$ & $10(6-40)$ & 0.011 \\
\hline
\end{tabular}

SSI: Surgical site infection; OC: open surgery; LAC: laparoscopic surgery. *Clavien-Dindo classification, grade 2 or more.

for obese patients was acceptable. To date, there have been no randomized-controlled trials comparing LAC and OC for colorectal cancer in obese patients, and only limited numbers of retrospective studies have been performed $(6,9,11,16-18)$.

In the present study, the LAC group had significantly longer operative time; nevertheless, it had less blood loss and shorter hospital stays than did the OC group. Vignali et al. compared surgical results of patients with BMI $>30 \mathrm{~kg} / \mathrm{m}^{2}$ who underwent LAC and OC for colorectal cancer. They found that the operative time was on average 29 minutes longer, blood loss was $78 \mathrm{ml}$ less and hospital stays were 2.4 days shorter for the LAC group (19). Our findings corroborate their results.

In terms of postoperative complications, we observed no differences when all complications were considered. Nevertheless, two types of complication were theoretically expected to decrease, ileus and SSI. Ileus was the most frequent complication in both groups and rates were similar 
Table IV. Sites of recurrence.

\begin{tabular}{lccc}
\hline Factor & $\begin{array}{c}\text { OC (N=64), } \\
\mathrm{n}(\%)\end{array}$ & $\begin{array}{c}\text { LAC (N=32), } \\
\mathrm{n}(\%)\end{array}$ & $p$-Value \\
\hline Recurrence & $9(14.1 \%)$ & $3(9.4 \%)$ & 0.745 \\
$\quad$ Liver & $5(7.8 \%)$ & $1(3.1 \%)$ & \\
Lung & $2(3.1 \%)$ & $1(3.1 \%)$ & \\
Local site & $2(3.1 \%)$ & 0 & \\
Peritoneum & 0 & $1(3.1 \%)$ & \\
Extra-regional & $1(1.6 \%)$ & 0 & \\
lymph node & & & \\
\hline
\end{tabular}

OC: Open surgery; LAC: laparoscopic surgery.

for the two groups $(12.3 \%$ vs. $12.5 \%)$ in accordance with the results of previous reports $(12,19)$. If there were longer follow-up, we might have been able to demonstrate significant superiority of LAC in terms of risk of ileus due to adhesions, as Christopher et al. reported (20), because of the smaller degree of intra-abdominal trauma introduced by LAC. Some studies showed that LAC was associated with lower risk of SSI than was OC [Vignali et al. (12), 8.2\% vs. 15.4\%; Yantao et al. (19), 17\% vs. 31\%]. In the current study, the rate of SSI was very small and there was no difference between the groups. In our procedure, careful lavage of the wound was standard in both approaches; in OC, a subcutaneous drainage tube was often placed at the surgeon's discretion; therefore, it is possible that superiority of LAC to OC in terms of SSI risk was masked. Some researchers suggested the possibility that Trendelenburg position and pneumoperitoneum can theoretically worsen results in obese patients undergoing LAC; nevertheless, in the current study, we did not demonstrate increased incidence of cardiopulmonary complications. Considering these facts, the short-term benefits associated with LAC also appear to apply to the obese population.

In the present study, the oncological outcomes were similar for both groups, whereas JCOG0404 reported that LAC had poorer outcomes than OC in obese patients (21). The reasons why our results differ from those of JCOG0404 are not clear. Nevertheless, we speculate that one reason may be the heterogeneity of surgical quality. As opposed to OC, in LAC, there are differences in surgical quality that have an impact on oncological outcomes; the JCOG0404 investigators reported a gap in oncological results between institutions. Currently, it is accepted that CME and CVL are essential, and noncompletion of these procedures can lead to worse oncological outcomes. These facts suggest that obesity may demand technical maturity on the part of the surgical team in order to accomplish clean CME and CVL; even in the JCOG0404 groups, some teams were unable to accomplish these tasks, especially in obese patients.

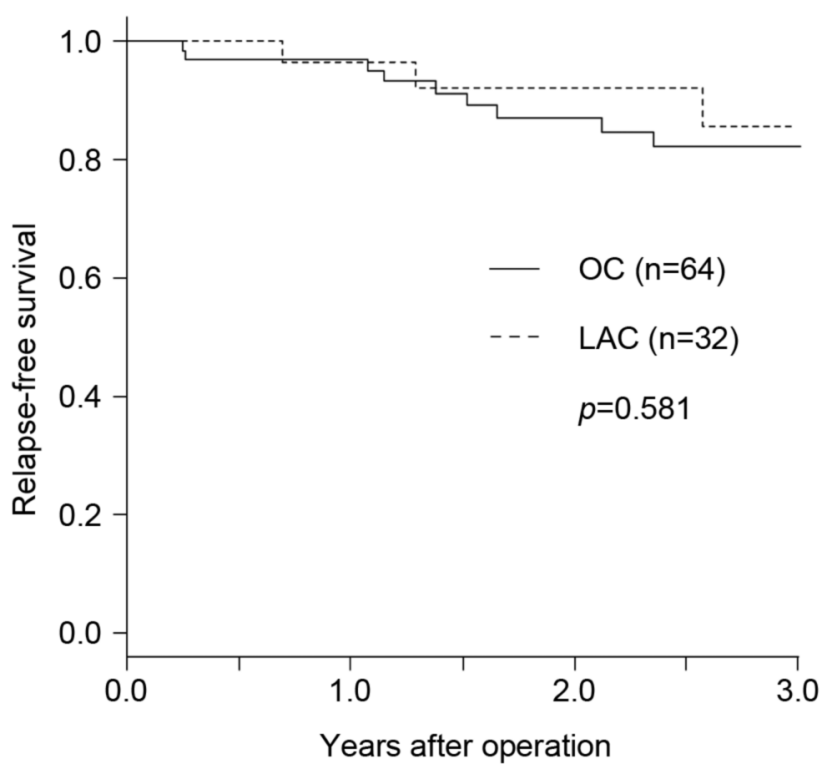

Figure 2. Relapse-free survival rates in the open $(O C)$ and laparoscopic (LAC) surgery groups. The 3-year relapse-free survival rates were $82.2 \%$ and $85.5 \%$, respectively.

As we reported previously, in the surgical groups at our associated hospitals, we employ standardized operative procedures and hold periodic meetings to discuss improving LAC procedures $(22,23)$. In obese patients, assistants should recognize that the effective point to grasp tissue in order to obtain adequate surgical views is strictly limited, and the surgeon should recognize that the length of tissue that can be cut in one task is very narrow. Together, as a team, more frequent changes of surgical views to obtain safe views should be made than in procedures performed on non-obese patients. Sharing these points with the team and the group might have made our results better and more homogeneous.

Some limitations with the present study should be observed when interpreting these results. The first limitation is selection bias. We did not obtain details regarding the surgeon and assistants at each operation. For LAC, skilled operators and assistants might be selected more preferentially than would be the case for OC. Secondly, after matching, most patients with preoperative ileus had been excluded from this study, mainly in the open surgery group. This suggests that patient backgrounds in this study may differ from those of other clinical settings; to remedy this limitation, another investigation should be performed including patients with preoperative ileus. A third limitation is in regard to the definition of obesity. In the present study, BMI $\geq 25 \mathrm{~kg} / \mathrm{m}^{2}$ was defined as obesity, whereas many European countries adopt BMI $\geq 30 \mathrm{~kg} / \mathrm{m}^{2}$. Recently, some investigators have reported visceral fat accumulation rather than BMI as the important 
factor determining technical maturity for performing LAC (24). Asians are reported to have a different distribution of adipose tissue from Europeans and have lower visceral fat accumulation than European patients with the same BMI $(25,26)$. In addition, unlike Europeans, Asians have more comorbidities due to obesity when their BMI increases more than $25 \mathrm{~kg} / \mathrm{m}^{2}$ (27). For these reasons, we adopted BMI $\geq 25 \mathrm{~kg} / \mathrm{m}^{2}$ as our definition of obesity. Nevertheless, the results of the present study may not always apply to obesity defined differently.

In conclusion, our study suggests that laparoscopic surgery for obese patients with colon cancer provided equivalent oncological safety and advantages in terms of short-term outcomes compared with open surgery, and therefore should be offered as an alternative procedure.

\section{Conflicts of Interest}

Drs. Keisuke Kazama, Masakatsu Numata, Toru Aoyama, Atsushi Onodeara, Kentaro Hara, Yosuke Atsumi, Hiroshi Tamagawa, Teni Godai, Hiroyuki Saeki, Yusuke Saigusa, Hironao Okamoto, Manabu Shiozawa, Takashi Oshima, Norio Yukawa, Munetaka Masuda and Yasushi Rino declare no conflicts of interest or financial ties to disclose.

\section{Authors' Contributions}

Keisuke Kazama: Contribution to conception of the work, collection of data, statistical analysis and writing article; Masakatsu Numata: Conception of the work, collection and evaluation of data; Toru Aoyama, Atsushi Onodeara, Kentaro Hara, Yosuke Atsumi, Hiroshi Tamagawa, Hironao Okamoto, Teni Godai, Hiroyuki Saeki: Collection of data; Yusuke Saigusa: Statistical analysis; Manabu Shiozawa, Takashi Oshima, Norio Yukawa, Munetaka Masuda and Yasushi Rino: Collection and evaluation of data.

\section{Acknowledgements}

This work was supported, in part, by the nongovernmental organization Yokohama Surgical Research Group, Dr. Masumi Kamachi (Tokyo Shinagawa Hospital), Dr. Ryuji Tominaga (Fukuoka Wajiro Hospital), and Dr. Nobuko Yoshiki (Yoshiki Dermatology Clinic Ginza).

\section{References}

1 Clinical Outcomes of Surgical Therapy Study Group, Nelson H, Sargent DJ, Wieand HS, Fleshman J, Anvari M, Stryker SJ, Beart RW Jr., Hellinger M, Flanagan R Jr., Peters W and Ota D: A comparison of laparoscopically assisted and open colectomy for colon cancer. N Engl J Med 350(20): 2050-2059, 2004. PMID: 15141043. DOI: 10.1056/NEJMoa032651

2 Lacy AM, Delgado S, Castells A, Prins HA, Arroyo V, Ibarzabal A and Pique JM: The long-term results of a randomized clinical trial of laparoscopy-assisted versus open surgery for colon cancer. Ann Surg 248(1): 1-7, 2008. PMID: 18580199. DOI: 10.1097/SLA.0b013e31816a9d65
3 Leung KL, Lai PB, Ho RL, Meng WC, Yiu RY, Lee JF and Lau WY: Systemic cytokine response after laparoscopic-assisted resection of rectosigmoid carcinoma: A prospective randomized trial. Ann Surg 231(9416): 506-511, 2000. PMID: 10749610. DOI: $10.1097 / 00000658-200004000-00008$

4 Jayne DG, Guillou PJ, Thorpe H, Quirke P, Copeland J, Smith AM, Heath RM, Brown JM and UK MRC CLASICC Trial Group: Randomized trial of laparoscopic-assisted resection of colorectal carcinoma: 3-Year results of the UK MRC CLASICC Trial Group. J Clin Oncol 25(21): 3061-3068, 2007. PMID: 17634484. DOI: $10.1200 / \mathrm{JCO} .2006 .09 .7758$

5 NCD Risk Factor Collaboration (NCD-RisC): Trends in adult body-mass index in 200 countries from 1975 to 2014: A pooled analysis of 1698 population-based measurement studies with 19.2 million participants. Lancet 387(10026): 1377-1396, 2016. PMID: 27115820. DOI: 10.1016/S0140-6736(16)30054-X

6 He Y, Wang J, Bian H, Deng X and Wang Z: BMI as a predictor for perioperative outcome of laparoscopic colorectal surgery: A pooled analysis of comparative studies. Dis Colon Rectum 60(4): 433-445, 2017. PMID: 28267012. DOI: 10.1097/ DCR.0000000000000760

7 Sakamoto K, Niwa S, Tanaka M, Goto M, Sengoku H and Tomiki Y: Influence of obesity on the short-term outcome of laparoscopic colectomy for colorectal cancer. J Minim Access Surg 3(3): 98-103, 2007 PMID: 19789665. DOI: 10.4103/09729941.37192

8 Yang T, Wei M, He Y, Deng X and Wang Z: Impact of visceral obesity on outcomes of laparoscopic colorectal surgery: A metaanalysis. ANZ J Surg 85(7-8): 507-513, 2015. PMID: 25902904. DOI: $10.1111 /$ ans.13132

9 Makino T, Shukla PJ, Rubino F and Milsom JW: The impact of obesity on perioperative outcomes after laparoscopic colorectal resection. Ann Surg 255(2): 228-236, 2012. PMID: 22190113. DOI: $10.1097 /$ sla.0b013e31823dcbf7

10 Choi BJ, Jeong WJ, Kim SJ and Lee SC: Impact of obesity on the short-term outcomes of single-port laparoscopic colectomy for colorectal cancer in the Asian population: A retrospective cohort study. Medicine 96: e6649, 2017. PMID: 28700463. DOI: 10.1097/MD.0000000000006649

11 Fung A, Trabulsi N, Morris M, Garfinkle R, Saleem A, Wexner $\mathrm{SD}$, Vasilevsky CA and Boutros M: Laparoscopic colorectal cancer resections in the obese: A systematic review. Surg Endosc 31(5): 2072-2088, 2017. PMID: 27778169. DOI: 10.1007/ s00464-016-5209-y

12 Cai Y, Zhou Y, Li Z, Xiang J and Chen Z: Surgical outcome of laparoscopic colectomy for colorectal cancer in obese patients: A comparative study with open colectomy. Oncol Lett 6(4): 1057-1062, 2013. PMID: 24137464. DOI: 10.3892/ol.2013.1508

13 Kitano S, Inomata M, Mizusawa J, Katayama H, Watanabe M, Yamamoto S, Ito M, Saito S, Fujii S, Konishi F, Saida Y, Hasegawa H, Akagi T, Sugihara K, Yamaguchi T, Masaki T, Fukunaga Y, Murata K, Okajima M, Moriya Y and Shimada Y: Survival outcomes following laparoscopic versus open D3 dissection for stage II or III colon cancer (JCOG0404): A phase 3, randomised controlled trial. Lancet Gastroenterol Hepatol 2(4): 261-268, 2017. PMID: 28404155. DOI: 10.1016/S2468-1253(16)30207-2

14 Hashiguchi Y, Muro K, Saito Y, Ito Y, Ajioka Y, Hamaguchi T, Hasegawa K, Hotta K, Ishida H, Ishiguro M, Ishihara S, Kanemitsu Y, Kinugasa Y, Murofushi K, Nakajima TE, Oka S, Tanaka T, Taniguchi H, Tsuji A, Uehara K, Ueno H, Yamanaka T, Yamazaki 
K, Yoshida M, Yoshino T, Itabashi M, Sakamaki K, Sano K, Shimada Y, Tanaka S, Uetake H, Yamaguchi S, Yamaguchi N, Kobayashi H, Matsuda K, Kotake K, Sugihara K and Japanese Society for Cancer of the Colon and Rectum: Japanese Society for Cancer of the Colon and Rectum (JSCCR) guidelines 2019 for the treatment of colorectal cancer. Int J Clin Oncol. 25(1): 1-42, 2020. PMID: 31203527. DOI: 10.1007/s10147-019-01485-Z

15 Dindo D, Demartines N and Clavien PA: Classification of surgical complications: A new proposal with evaluation in a cohort of 6336 patients and results of a survey. Ann Surg 240: 205-213, 2004. PMID: 15273542. DOI: 10.1097/01.sla. 0000133083.54934.ae

16 Akiyoshi T, Ueno M, Fukunaga Y, Nagayama S, Fujimoto Y, Konishi T, Kuroyanagi $\mathrm{H}$ and Yamaguchi T: Effect of body mass index on short-term outcomes of patients undergoing laparoscopic resection for colorectal cancer: A single-institution experience in Japan. Surg Laparosc Endosc Percutan Tech 21(6): 409-414, 2011. PMID: 22146162. DOI: 10.1097/SLE.0b013e31822e5fdc

17 Bell S, Kong JC, Wale R, Staples M, Oliva K, Wilkins S, Mc Murrick P and Warrier SK: The effect of increasing body mass index on laparoscopic surgery for colon and rectal cancer. Colorectal Dis 20(9): 778-788, 2018. PMID: 29577556. DOI: 10.1111/codi.14107

18 Hotouras A, Ribas Y, Zakeri SA, Nunes QM, Murphy J, Bhan C and Wexner SD: The influence of obesity and body mass index on the outcome of laparoscopic colorectal surgery: A systematic literature review. Colorectal Dis 18(10): O337-O366, 2016. PMID: 27254110. DOI: 10.1111/codi.13406

19 Vignali A, De Nardi P, Ghirardelli L, Di Palo S and Staudacher C: Short and long-term outcomes of laparoscopic colectomy in obese patients. World J Gastroenterol 19(42): 7405-7411, 2013. PMID: 24259971. DOI: 10.3748/wjg.v19.i42.7405

20 Aquina CT, Probst CP, Becerra AZ, Iannuzzi JC, Hensley BJ, Noyes K, Monson JR and Fleming FJ: Missed opportunity: Laparoscopic colorectal resection is associated with lower incidence of small bowel obstruction compared to an open approach. Ann Surg 264(1): 127-34, 2016. PMID: 26421688. DOI: $10.1097 /$ SLA.0000000000001389

21 Nishizawa Y, Akagi T, Inomata M, Katayama H, Mizusawa J, Yamamoto S, Ito M, Masaki T, Watanabe M, Shimada Y and Kitano S: Risk factors for early postoperative complications after D3 dissection for stage II or III colon cancer: Supplementary analysis of a multicenter randomized controlled trial in Japan (JCOG0404). Ann Gastroenterol Surg 3(3): 310-317, 2019. PMID: 31131360 . DOI: 10.1002/ags3.12246
22 Kazama K, Aoyama T, Hayashi T, Yamada T, Numata M, Amano S, Kamiya M, Sato T, Yoshikawa T, Shiozawa M, Oshima T, Yukawa N, Rino Y and Masuda M: Evaluation of short-term outcomes of laparoscopic-assisted surgery for colorectal cancer in elderly patients aged over 75 years old: A multi-institutional study (YSURG1401). BMC Surg 17(1): 29, 2017. PMID: 28327119. DOI: 10.1186/s12893-017-0229-7

23 Numata M, Hasuo K, Hara K, Maezawa Y, Kazama K, Inari H, Takata K, Jin Y, Yukawa N, Oshima T, Rino Y, Taguri M and Masuda M: A propensity score-matching analysis comparing the oncological outcomes of laparoscopic and open surgery in patients with stage I/II colon and upper rectal cancers. Surg Today 45(6): 700-707, 2015. PMID: 24980115. DOI: $10.1007 /$ s00595-014-0954-9

24 Watanabe J, Tatsumi K, Ota M, Suwa Y, Suzuki S, Watanabe A, Ishibe A, Watanabe K, Akiyama H, Ichikawa $\mathrm{Y}$ and Morita S: The impact of visceral obesity on surgical outcomes of laparoscopic surgery for colon cancer. Int J Colorectal Dis 29(3): 343-351, 2014. PMID: 24297037. DOI: 10.1007/s00384-013-1803-9

25 Deurenberg P, Deurenberg-Yap M and Guricci S: Asians are different from Caucasians and from each other in their body mass index/body fat percent relationship. Obes Rev 3(3): 141146, 2002. PMID: 12164465. DOI: 10.1046/j.1467-789x.2002. 00065.x

26 Fujimoto WY, Bergstrom RW, Boyko EJ, Leonetti DL, NewellMorris LL and Wahl PW: Susceptibility to development of central adiposity among populations. Obes Res 3 Suppl 2: 179S186S, 1995. PMID: 8581774. DOI: 10.1002/j.1550-8528.1995. tb00461.x

27 Examination Committee of Criteria for "Obesity Disease" in Japan; Japan Society for the Study of Obesity: New criteria for "obesity disease" in Japan. Circ J 66(11): 987-992, 2002. PMID: 12419927. DOI: $10.1253 /$ circj.66.987
Received March 28, 2020

Revised April 9, 2020

Accepted April 13, 2020 